\title{
Candida cellulosicola sp. nov., a xylose-utilizing anamorphic yeast from rotten wood
}

Correspondence
Feng-Yan Bai
baify@im.ac.cn
Xinyan Guo, ${ }^{1,2}$ Hongkun Zhu ${ }^{3}$ and Feng-Yan Bai ${ }^{1}$

\author{
${ }^{1}$ State Key Laboratory of Mycology, Institute of Microbiology, \\ Chinese Academy of Sciences, Beijing 100101, PR China \\ ${ }^{2}$ Graduate School of the Chinese Academy of Sciences, Beijing 100039, PR China \\ ${ }^{3}$ Honors Program for Life Science, China Agricultural University, Beijing 100193, PR China
}

\begin{abstract}
Two xylose-utilizing yeast strains isolated from rotten wood collected in the rainforest in different mountains of Hainan province, southern China, were studied. Sequence analysis of the large subunit rDNA D1/D2 domain and internal transcribed spacer region revealed that the strains represent a novel anamorphic yeast species, for which the name Candida cellulosicola sp. nov. is proposed; the type strain is HNX16-2 ${ }^{\top}$ (=CGMCC $2.3503^{\top}=$ CBS $11952^{\top}$ ). Phylogenetically, the novel species was closely related to a xylose-utilizing teleomorphic ascomycetous yeast species Spencermartinsiella europaea in the family Trichomonascaceae, but differed from the latter by $3.0 \%$ mismatches in the D1/D2 domain.
\end{abstract}

Forest habitats such as rotten wood and plant litter containing plenty of assimilable carbon compounds are expected to harbour diverse yeasts, including pentoseutilizing or -fermenting species. These yeasts are of potential value in bio-ethanol production from lignocellulose materials. During an ecological survey on microfungi colonizing rotten wood in the rainforest of southern Chile, Dill et al. (1984) and Ramírez \& González (1984a, b, c) described a total of 18 novel yeast species (Middelhoven, 2006). Of the six novel methanol-assimilating ascomycetous yeast species from wood material described by Péter et al. (2003), four were isolated from rotten wood. Middelhoven \& Kurtzman (2007) identified two novel ascomycetous yeast species from strains isolated from rotten wood. In recent years, new xylose- or cellobiose-fermenting yeast species have been isolated from rotting wood in Brazil and the Atlantic rainforest (Barbosa et al., 2009; Cadete et al., 2009; Santos et al., 2011). In an effort to investigate the biodiversity of yeasts inhabiting rotten wood in the rainforest of Hainan, a tropical island in southern China, a variety of undescribed yeast species were isolated (Wang \& Bai, 2009); two of them have been described previously (Wang et al., 2009). A further novel anamorphic ascomycetous yeast species represented by two of the Hainan strains from rotten wood is described in this study.

Yeasts were isolated using the enrichment method selective for xylose-utilizing strains. Rotten wood samples were put in enrichment medium containing: $1 \%(\mathrm{w} / \mathrm{v})$ yeast

Abbreviation: ITS, internal transcribed spacer.

The GenBank/EMBL/DDBJ accession numbers for the ITS region and $26 S$ rDNA D1/D2 domain sequences of strains HNX16-2 ${ }^{\top}$ and HNX35-3 are HM151013-HM151016. nitrogen base (Difco), $2 \%(\mathrm{w} / \mathrm{v})$ xylose and $200 \mu \mathrm{g}$ chloromycetin $\mathrm{ml}^{-1}$. After incubation at $25{ }^{\circ} \mathrm{C}$ for 7-14 days, aliquots $(200 \mu \mathrm{l})$ of $10^{-1}$ to $10^{-3}$ diluted enrichment medium were spread on agar plates that were prepared using enrichment medium plus $2 \%$ agar. After incubation of the plates for $2-5$ days at $25{ }^{\circ} \mathrm{C}$, yeast colonies with different morphological characters were selected for further study.

Strains HNX16-2 ${ }^{\mathrm{T}}$ and HNX35-3 were isolated from two different rotten wood samples of broad-leaved trees collected in Wuzhi and Diaoluo Mountains, respectively. The two mountains, which are approximately $30 \mathrm{~km}$ apart, are located in Hainan province, southern China. Morphological, physiological and biochemical characteristics were examined according to standard methods commonly used in yeast taxonomy (Yarrow, 1998). Assimilation of nitrogen compounds was investigated on solid media with starved inocula (Nakase \& Suzuki, 1986).

Nuclear DNA was extracted by the method of Makimura et al. (1994). Sequencing of the internal transcribed spacer (ITS) region (including 5.8S rDNA) and the large-subunit rDNA D1/D2 domain, and molecular phylogenetic analysis were performed as described previously (Wu et al., 2006). Reference sequences were retrieved from GenBank (accession numbers are given in Fig. 1). Sequences were selected based on the result of a BLAST search through GenBank with the D1/D2 sequence of strain HNX16-2 $2^{\mathrm{T}}$ as the query and on previous related studies (Kurtzman, 2007; Kurtzman \& Robnett, 2007; Péter et al., 2011).

Strains HNX16-2 $2^{\mathrm{T}}$ and HNX35-3 exhibited identical sequences in both D1/D2 and ITS regions, indicating their conspecificity. In the phylogenetic tree constructed from D1/D2 sequences, strain HNX16- $2^{\mathrm{T}}$ formed a clade with 


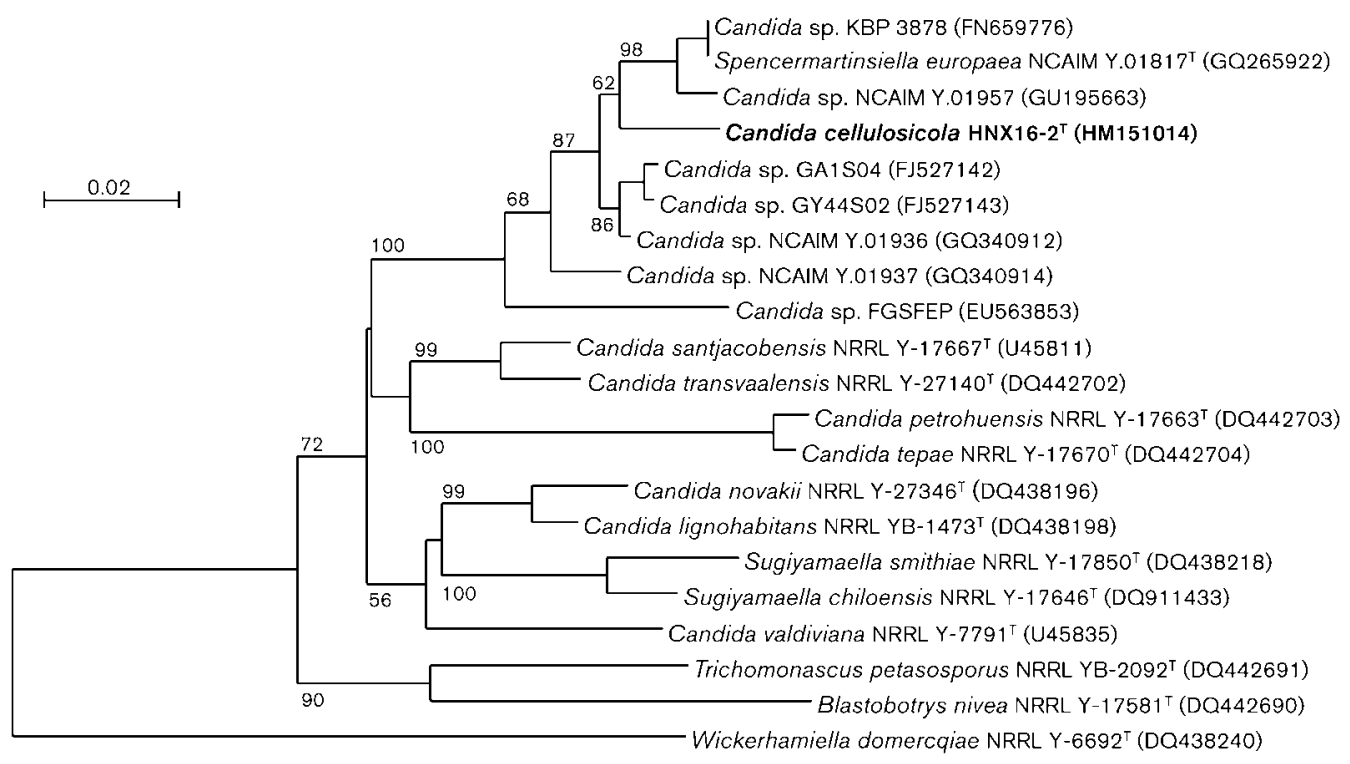

Fig. 1. Phylogenetic tree drawn from neighbour-joining analysis of $26 S$ rDNA D1/D2 domain sequences depicting the relationship of Candida cellulosicola sp. nov. with closely related taxa. Bootstrap values (\%) over $50 \%$ from 1000 bootstrap replicates are shown. Reference sequences were retrieved from GenBank under the accession numbers indicated. Bar, 0.02 nucleotide substitutions per position.

the newly described teleomorphic ascomycetous yeast species Spencermartinsiella europaea (Péter et al., 2011) and a few undescribed yeast strains with $100 \%$ bootstrap support (Fig. 1). This clade belongs to the family Trichomonascaceae (Kurtzman \& Robnett, 2007). In the 572 bp D1/D2 domain sequenced, strain HNX16-2 $2^{\mathrm{T}}$ differed from S. europaea NCAIM Y. $01817^{\mathrm{T}}$ by $17(3.0 \%)$ mismatches (14 substitutions and 3 indels) and from other undescribed strains of this clade by $2.3-4.0 \%$ mismatches. In the ITS region, strain HNX16-2 ${ }^{\mathrm{T}}$ differed from $S$. europaea NCAIM Y.01817 ${ }^{\mathrm{T}}$ by $16.5 \%$ mismatches and from two other closely related strains, Candida spp. GY44S02 and GA1S04, by $13 \%$ mismatches.

The yeast species closely related to strains $\mathrm{HNX} 16-2^{\mathrm{T}}$ and HNX35-3 generally had a common ecological habitat, i.e. associated with rotten wood. S. europaea, the closest relative among the recognized species, was isolated from rotten wood collected in Hungary (Péter et al., 2011). The undescribed strains located in the Spencermartinsiella clade were also mostly isolated from rotten wood (G. Péter and C. F. Lee, personal communication). Other close relatives of the Spencermartinsiella clade included in the tree (Fig. 1), mostly belonging to members of the Sugiyamaella clade, were also isolated from rotten wood or related habitats, such as wood-ingesting insects and insect frass (Kurtzman, 2007; Kurtzman \& Robnett, 2007; Suh et al., 2005; Wang et al., 2010).

Strains HNX16-2 $2^{\mathrm{T}}$ and HNX35-3 also possessed the morphological and physiological criteria characterized in the Spencermartinsiella and closely related Sugiyamaella clades. In addition to cells that reproduced by multilateral budding (Fig. 2a), the novel species formed hyphae and pseudohyphae on various media including malt extract agar, corn meal agar and V8 juice agar. Blastoconidia produced on denticulate conidiogenous cells, which are usually observed in species of the closely related genera Sugiyamaella, Spencermartinsiella and Trichomonascus and their anamorphs (Kurtzman \& Robnett, 2007; Péter et al., 2011), were also observed in the two strains studied (Fig. $2 b)$. However, the sexual state was not found for single or mixed cultures of the two strains on any of the sporulation media used, including McClary acetate agar, 5\% malt extract agar, corn meal agar and diluted $(1: 4$ and $1: 19) \mathrm{V} 8$ juice agar, which were incubated at $25{ }^{\circ} \mathrm{C}$ for 2 months and observed at weekly intervals.

Physiologically, strains HNX16-2 ${ }^{\mathrm{T}}$ and HNX35-3 were similar to the closely related species in the Spencermartinsiella and Sugiyamaella clades with positive xylose and cellobiose assimilation reactions but a negative methanol assimilation reaction (Kurtzman, 2007; Péter et al., 2011). However, strains HNX16-2 ${ }^{\mathrm{T}}$ and HNX35-3 differed from the most closely related species Spencermartinsiella europaea in their inability to use L- and D-arabinose and hexadecane and their ability to use inulin as sole carbon source.

The rDNA sequence and phenotypic comparisons made above indicate that strains HNX16-2 ${ }^{\mathrm{T}}$ and HNX35-3 represent a novel anamorphic yeast species in the Spencermartinsiella clade. According to the current taxonomic concept of ascomycetous yeasts (Kurtzman, 1998; Meyer et al., 1998), the name Candida cellulosicola sp. nov. is proposed. 

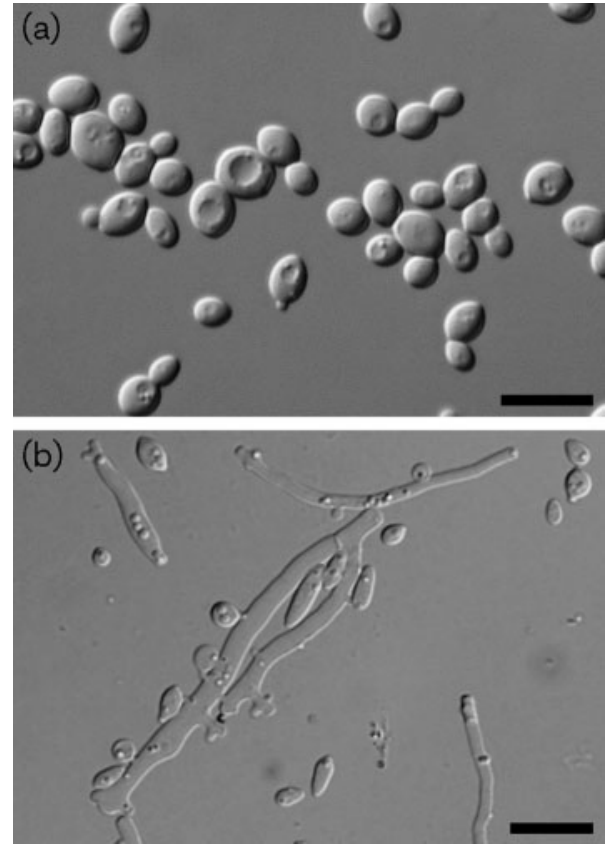

Fig. 2. Candida cellulosicola sp. nov. $\mathrm{HNX} 16-2^{\top}$. Budding cells (a) in YM broth after 2 days at $25^{\circ} \mathrm{C}$ and denticulate hyphae (b) on corn meal agar after 10 days at $25^{\circ} \mathrm{C}$. Bars, $10 \mu \mathrm{m}$.

\section{Latin diagnosis of Candida cellulosicola F.-Y. Bai et $X$. Guo sp. nov.}

In medio liquid $\mathrm{YM}$ post dies 3 and $25{ }^{\circ} \mathrm{C}$, cellulae ovoideae aut ellipsoideae, $2.5-8.75 \times 2.5-12.5 \mu \mathrm{m}$, singulae, binae et adhaerentes. Per gemmationem multipolarem reproducentes. Blastoconidia saepe ex cellulis conidiogenis denticulatis oriuntur. Post 1 mensem sedimentum formatur. In agaro YM post 1 mensem ad $25^{\circ} \mathrm{C}$, candida vel cremea, glabra. Centrum coloniae sublatum est, margine inetegro vel leviter lobata et fimbriata cum mycelio. In agaro farinae Zea mayidis, pseudohyphae et hyphae septatae formantur. Asci nulla. Glucosum non fermentatur. Glucosum, sucrosum, maltosum, cellobiosum, trehalosum, galactosum, melibiosum, raffinosum, melezitosum, D-xylosum, L-rhamnosum, L-sorbosum, lactosum (lente), D-ribosum, erythritolum, galactitolum (lente), glycerolum, D-mannitolum, D-sorbitolum, ribitolum, salicinum (infirme), acidum succinicum, inulinum, D-glucosaminum (infirme), D-glucitolum (infirme) et acidum citricum assimilantur at non amylum solubile, acidum DL-lacticum, L-arabinosum, D-arabinosum, inositolum, methanolum, ethanolum, hexadecanum, methyl $\alpha$-D-glucosidum nec galactitolum. Ammonium sulfatum, L-lysinum, ethylaminum assimilantur at non kalium nitricum, natrum nitrosum et cadaverinum. Vitamina externa ad crescentiam necessaria non sunt. Maxima temperatura crescentiae: $33{ }^{\circ} \mathrm{C}$. Materia amyloidea iodophila non formatur.

Typus: isolatus ex ligno, HNX16-2 $2^{\mathrm{T}}\left(=\mathrm{CBS} 11952^{\mathrm{T}}\right)$, depositus in collectione China General Microbiological Culture Collection Center, Academia Sinica $\left(\right.$ CGMCC $\left.2.3503^{\mathrm{T}}\right)$.

\section{Description of Candida cellulosicola F.-Y. Bai \& X. Guo sp. nov.}

Candida cellulosicola [cel.lu.lo.si'co.la. N.L. n. cellulosum cellulose; L. suff. cola (from L. n. incola) inhabitant, dweller; N.L. n. cellulosicola cellulose-dweller, referring to the substrate from which the type strain was isolated].

In YM broth (Yarrow, 1998), after 3 days at $25^{\circ} \mathrm{C}$, cells are oval and ellipsoid, 2.5-8.75 $\times 2.5-12.5 \mu \mathrm{m}$ and occur singly, in pairs or in groups (Fig. 2). Budding is multilateral. Blastoconidia produced on denticulate conidiogenous cells are present. After 1 month at $25^{\circ} \mathrm{C}$, sediment is present. On YM agar, after 1 month at $25^{\circ} \mathrm{C}$, the streak culture is white to cream and smooth. The edge is finely lobed and fringed with filament. In Dalmau plate culture on corn meal agar, true hyphae and pseudohyphae are formed after 10 days at $25{ }^{\circ} \mathrm{C}$. Ascospores are not formed. Glucose is not fermented. Glucose, sucrose, maltose, cellobiose, trehalose, galactose, melibiose, raffinose, melezitose, D-xylose, L-rhamnose, L-sorbose, lactose (delayed), D-ribose, erythritol, galactitol (delayed), glycerol, D-mannitol, D-sorbitol, ribitol, salicin (weak), succinate, inulin, D-glucosamine (weak), D-glucitol (weak) and citrate are assimilated; soluble starch, DL-lactate, L-arabinose, Darabinose, inositol, methanol, ethanol, hexadecane, methyl $\alpha$-D-glucoside and galactitol are not assimilated. Ammonium sulfate, L-lysine and ethylamine hydrochloride are assimilated; potassium nitrate, sodium nitrite and cadaverine hydrochloride are not assimilated. Growth in vitaminfree medium is positive. Maximum growth temperature is $33{ }^{\circ} \mathrm{C}$. Starch-like compounds are not produced.

The type strain is HNX16-2 ${ }^{\mathrm{T}}\left(=\mathrm{CGMCC} 2.3503^{\mathrm{T}}=\mathrm{CBS}\right.$ $11952^{\mathrm{T}}$ ), isolated from rotten wood collected from a rainforest, Hainan province, China, in July 2007.

\section{Acknowledgements}

This study was supported by the National Natural Science Foundation of China (NSFC), grant no. 30825002.

\section{References}

Barbosa, A. C., Cadete, R. M., Gomes, F. C., Lachance, M. A. \& Rosa, C. A. (2009). Candida materiae sp. nov., a yeast species isolated from rotting wood in the Atlantic Rain Forest. Int J Syst Evol Microbiol 59, 2104-2106.

Cadete, R. M., Santos, R. O., Melo, M. A., Mouro, A., Gonçalves, D. L., Stambuk, B. U., Gomes, F. C., Lachance, M. A. \& Rosa, C. A. (2009). Spathaspora arborariae sp. nov., a D-xylose-fermenting yeast species isolated from rotting wood in Brazil. FEM Yeast Res 9, 1338-1342.

Dill, I., Ramírez, C. \& González, A. (1984). Candida lignophila sp. nov., a new basidiomycetous yeast anamorph from rotting wood of Drimys winteri. Antonie van Leeuwenhoek 50, 219-225.

Kurtzman, C. P. (1998). Discussion of teleomorphic and anamorphic ascomycetous yeasts and a key to genera. In The Yeasts, a Taxonomic Study, 4th edn, pp. 111-121. Edited by C. P. Kurtzman \& J. W. Fell. Amsterdam: Elsevier. 
Kurtzman, C. P. (2007). Eleven new species of Sugiyamaella and Candida from forest habitats. FEM Yeast Res 7, 1046-1063.

Kurtzman, C. P. \& Robnett, C. J. (2007). Multigene phylogenetic analysis of the Trichomonascus, Wickerhamiella and Zygoascus yeast clades, and the proposal of Sugiyamaella gen. nov. and 14 new species combinations. FEM Yeast Res 7, 141-151.

Makimura, K., Murayama, S. Y. \& Yamaguchi, H. (1994). Detection of a wide range of medically important fungi by the polymerase chain reaction. J Med Microbiol 40, 358-364.

Meyer, S. A., Payne, R. W. \& Yarrow, D. (1998). Candida Berkhout. In The Yeasts, a Taxonomic Study, 4th edn, pp. 454-573. Edited by C. P. Kurtzman \& J. W. Fell. Amsterdam: Elsevier.

Middelhoven, W. J. (2006). Polysaccharides and phenolic compounds as substrate for yeasts isolated from rotten wood and description of Cryptococcus fagi sp. nov. Antonie van Leeuwenhoek 90, 57-67.

Middelhoven, W. J. \& Kurtzman, C. P. (2007). Four novel yeasts from decaying organic matter: Blastobotrys robertii sp. nov., Candida cretensis sp. nov., Candida scorzettiae sp. nov. and Candida vadensis sp. nov. Antonie van Leeuwenhoek 92, 233-244.

Nakase, T. \& Suzuki, M. (1986). Bullera megalospora, a new species of yeast forming large ballistospores isolated from dead leaves of Oryza sativa, Miscanthus sinensis, and Sasa sp. in Japan. J Gen Appl Microbiol 32, 225-240.

Péter, G., Tornai-Lehoczki, J., Fülöp, L. \& Dlauchy, D. (2003). Six new methanol assimilating yeast species from wood material. Antonie van Leeuwenhoek 84, 147-159.

Péter, G., Dlauchy, D., Tornai-Lehoczki, J., Suzuki, M. \& Kurtzman, C. P. (2011). Spencermartinsiella europaea gen. nov., sp. nov., a new member of the family Trichomonascaceae. Int J Syst Evol Microbiol 61, 993-1000.

Ramírez, C. \& González, A. (1984a). Two new species and one variety of nitrate-utilizing mycelial Candida isolated from decayed wood in the evergreen rainy Valdivian forest of southern Chile. Mycopathologia 88, 55-60.

Ramírez, C. \& González, A. (1984b). Three new filamentous, fermenting Candida isolated from decayed wood in the evergreen rainy Valdivian forest of southern Chile. Mycopathologia 88, 93-98.

Ramírez, C. \& González, A. (1984c). Five new filamentous, glucosefermenting Candida isolated from decayed wood in the evergreen rainy Valdivian forest of southern Chile. Mycopathologia 88, 83-92.

Santos, R. O., Cadete, R. M., Badotti, F., Mouro, A., Wallheim, D. O., Gomes, F. C., Stambuk, B. U., Lachance, M. A. \& Rosa, C. A. (2011). Candida queiroziae sp. nov., a cellobiose-fermenting yeast species isolated from rotting wood in Atlantic Rain Forest. Antonie van Leeuwenhoek 99, 635-642.

Suh, S.-O., McHugh, J. V., Pollock, D. D. \& Blackwell, M. (2005). The beetle gut: a hyperdiverse source of novel yeasts. Mycol Res 109, 261265.

Wang, C. \& Bai, F.-Y. (2009). Species diversity of yeasts from rotten wood in the rainforests of Hainan, China. Mycosystema 28, 354-362.

Wang, C., Wang, Q.-M., Jia, J.-H. \& Bai, F.-Y. (2009). Candida pseudocylindracea sp. nov. and Candida wuzhishanensis sp. nov. from Hainan Island, southern China. Mycosystema 28, 79-85.

Wang, S.-A., Li, F.-L. \& Bai, F.-Y. (2010). Candida laoshanensis sp. nov. and Candida qingdaonensis sp. nov., anamorphic, ascomycetous yeast species isolated from decayed wood. Int J Syst Evol Microbiol 60, 1697-1701.

Wu, Z.-W., Robert, V. \& Bai, F.-Y. (2006). Genetic diversity of the Pichia membranifaciens strains revealed from rRNA gene sequencing and electrophoretic karyotyping, and the proposal of Candida californica comb. nov. FEM Yeast Res 6, 305-311.

Yarrow, D. (1998). Methods for the isolation, maintenance and identification of yeasts. In The Yeasts, a Taxonomic Study, 4th edn, pp. 77-100. Edited by C. P. Kurtzman \& J. W. Fell. Amsterdam: Elsevier. 